\title{
A construção dos Fóruns de supervisão de estágio em serviço social
}

\author{
Reginaldo Guiraldelli \\ Universidade de Brasília (UnB)
}

Janaina Loeffler de Almeida

Secretaria de Planejamento do Estado de Mato Grosso (SEPLAN)

\begin{abstract}
A construção dos Fóruns de supervisão de estágio em serviço social
Resumo: Este artigo apresenta reflexões acerca da construção e fortalecimento dos Fóruns de Supervisão de Estágio como espaços político-formativos de interlocução, articulação, resistência e luta do Serviço Social brasileiro em defesa de uma formação crítica, pública, laica, presencial, democrática e de qualidade. Aborda o Fórum como um dos espaços estratégicos de organização e participação política da categoria, que contribui para o processo de formação continuada e de debates sobre estágio supervisionado. Com base em dados obtidos nos Fóruns realizados na regional centro-oeste, 2013-2014, são apresentados impasses e desafios para a consolidação dos fóruns, sinalizando a necessidade de estratégias coletivas, diante das adversidades postas na contemporaneidade que incidem na formação e exercício profissional.
\end{abstract}

Palavras-chave: Serviço Social. Formação profissional. Estágio. Fórum.

\section{The Construction of Internship Supervision Forums in Social Work}

Abstract: This article reflects on the construction and strengthening of Internship Supervision Forums as political-educational spaces for interlocution, articulation, resistance and struggle in Brazilian social work, in defense of critical, public, secular, classroom-based, democratic and quality education. It addresses supervision forums as one of the strategic spaces for political organization and participation for social workers, which contributes to the process of continuing education and debates about the supervised internship. Based on data obtained from Forums conducted in the Midwestern region, 2013-2014, the paper presents impasses and challenges to the consolidation of forums, indicating the need for collective strategies, considering the current adversities to professional education and exercise.

Keywords: Social Service. Professional Education. Internship. Forum. 


\section{Introdução}

Este artigo apresenta reflexões sobre a construção e o fortalecimento dos Fóruns de Supervisão de Estágio em Serviço Social, com base em experiências realizadas na regional centro-oeste no biênio 20132014ㄴ. Cabe considerar o cenário contemporâneo de crise capitalista e de profundas transformações societárias (NETTO, 1996) que incidem e alteram a dinâmica da vida social, rebatendo diretamente na formação e no exercício profissional de assistentes sociais, exigindo dessa categoria estratégias de articulação, resistência e luta coletiva. Dessa forma, o Fórum de Supervisão de Estágio ${ }^{2}$ é um espaço político-formativo fecundo e estratégico de articulação, luta e resistência coletiva de assistentes sociais, diante das adversidades e contradições postas na sociabilidade capitalista.

No que se refere ao entendimento de Fórum, ao buscarmos a raiz etimológica da palavra, identificamos que sua origem advém do latim e, na Roma Antiga, o fórum se referia à praça pública, espaço de encontro dos habitantes de uma determinada localidade, onde se discutiam questões de interesse da coletividade ${ }^{3}$. O Fórum é um lócus destinado aos debates públicos, é um espaço, por excelência, de reuniões, articulações, resistência, de formação continuada e discussões sobre assuntos de interesse coletivo. Assim, os Fóruns de Supervisão de Estágio em Serviço Social podem ser considerados espaços estratégicos de organização, articulação e participação da categoria profissional de assistentes sociais e estudantes, com o objetivo de discussão de questões candentes relacionadas à dinâmica social contemporânea e que se refletem na profissão, tanto no que se refere ao âmbito formativo, quanto ao exercício profissional. Reconhecendo os avanços e maturação no campo político-organizativo do Serviço Social brasileiro nas últimas décadas, a construção dos Fóruns de Supervisão emerge como demanda e necessidade da profissão de forma a contribuir para o debate da formação e do exercício profissional na dinâmica contraditória das relações sociais capitalistas.

Nessa perspectiva, apresentaremos algumas considerações sobre o processo de formação em Serviço Social, com ênfase para o estágio e, em seguida, problematizaremos o Fórum de Supervisão de Estágio enquanto espaço político-formativo estratégico de articulação coletiva, de resistência e luta. Também serão indicados alguns desafios para a consolidação dos Fóruns, sinalizando alternativas e estratégias para o seu fortalecimento.

\section{Formação em Serviço Social na contemporaneidade: o estágio em questão}

Compreender o movimento histórico da profissão e sua maturidade político-intelectual no cenário contemporâneo, com seus avanços, perspectivas, embates e desafios, exige da categoria a recusa da endogenia, do focalismo e da fragmentação. Por isso, numa perspectiva sócio-histórica, crítico-dialética e de totalidade, é necessário analisar o Serviço Social como profissão inserida no processo de produção e reprodução das relações sociais (IAMAMOTO, 2007), e, nesse caso, no capitalismo contemporâneo, marcado por constantes crises que incidem em todo o conjunto da vida social, ou seja, no mundo do trabalho, na relação Estadosociedade e nas formas como as classes sociais se organizam e disputam seus projetos.

Como elucida Yazbek (2009), a profissão surge no Brasil nos anos de 1930 com a emergência da questão social e, consequentemente, com a necessidade de respostas do Estado e da burguesia frente aos evidentes antagonismos postos na relação capital/trabalho e no acirramento da luta de classes. A questão social, objeto de intervenção e investigação da profissão, reconhecida nas Diretrizes Curriculares da ABEPSS de 1996 que orienta o projeto de formação e fundamenta o projeto ético-político é concebida como "expressão das desigualdades sociais constitutivas do capitalismo. Suas diversas manifestações são indissociáveis das relações entre as classes sociais que estruturam esse sistema e nesse sentido a questão social se expressa também na resistência e na disputa política" (YAZBEK, 2009, p. 127). Cabe ressaltar que nas primeiras décadas da emergência do Serviço Social no Brasil, houve a prevalência da concepção conservadora na profisssão, marcada pela influência neotomista, positivista e pragmática, em que se enfatizava a técnica e o metodologismo nas ações profissionais. Mudanças substantivas de concepção e de posicionamento político aconteceram com o Movimento latino-americano de Renovação da profissão na segunda metade do século 20, especialmente com o processo de intenção de ruptura (NETTO, 2001), que teve como um dos principais marcos o III Congresso Brasileiro de Assistentes Sociais (CBAS) realizado em São Paulo em 1979, mais conhecido como Congresso da Virada. Esse processo de Renovação no âmbito do Serviço Social não ocorreu de forma isolada e descontextualizada da conjuntura da época, e significou revisão da base teórica, metodológica, ideológica, técnica, ética e política da profissão, que se aproxima da tradição marxista (NETTO, 2001). É importante ressaltar também neste lastro histórico, o surgimento da pósgraduação em Serviço Social nos anos de 1970, que se expande nas últimas décadas, contribuindo para a produção de conhecimento na área, o que se traduz atualmente no relevante e qualitativo acervo bibliográfico que condensa o patrimônio intelectual da profissão. 
A partir desses acúmulos, a profissão vem construindo coletivamente um projeto ético-político alicerçado nos princípios do Código de Ética de 1993, na Lei de Regulamentação da Profissão n. 8662, também de 1993, e nas Diretrizes Curriculares da ABEPSS de 1996. Sobre o projeto ético-político, que conjuga dimensão formativa, política, ética e normativa, "É nos anos de 1990, porém, no duro embate com a ofensiva neoliberal que captura o Estado brasileiro, agravando ainda mais a histórica concentração de renda e suprimindo direitos garantidos em lei, que o projeto profissional do Serviço Social se consolida no país" (KOIKE, 2009, p. 209). Nessa esteira, a revisão das Diretrizes Curriculares (ABEPSS, 1996), baseada numa proposta de formação crítica, democrática, de qualidade, afinada com uma direção social, intelectual, ideopolítica e um projeto de sociedade emancipada, reconhece o estágio como componente curricular obrigatório. O estágio, reconhecida sua dimensão político-pedagógica, é uma atividade teórico-prática, que se caracteriza pela inserção de estudantes nos diversos espaços ocupacionais de atuação de assistentes sociais. É nesse momento do estágio que o estudante/estagiário se depara com as múltiplas expressões da questão social, objeto de investigação e intervenção profissional e, dessa forma, exercita sua capacidade analítica, crítica, propositiva e criativa. Por isso, o estagiário necessita de supervisão sistemática e contínua de um profissional inserido no espaço ocupacional de realização do estágio, denominado supervisor de campo, e da supervisão de um professor vinculado à sua instituição de ensino, denominado supervisor acadêmico.

As Diretrizes Curriculares (ABEPSS, 1996), sintoni-

...os Fóruns de Supervisão de

Estágio em Serviço Social podem ser considerados espaços estratégicos de organização, articulação e participação da categoria profissional de assistentes sociais e estudantes, com o objetivo de discussão de questões candentes relacionadas à dinâmica social contemporânea e que se refletem na profissão, tanto no que se refere ao âmbito formativo, quanto ao exercício profissional. zadas com as demandas sócio-históricas do tempo presente, também apregoam que a relação teoria-prática deve perpassar toda a formação profissional, com o objetivo de superar qualquer fragmentação e reducionismo no processo de ensino-aprendizagem. Para tanto, é preciso assegurar a indissociabilidade entre os núcleos de fundamentação, que são: 1) Núcleo de fundamentos teórico-metodológicos da vida social; 2) Núcleo de fundamentos da particularidade da formação sócio-histórica da sociedade brasileira e; 3) Núcleo de fundamentos do trabalho profissional. Isso significa que é inadmissível qualquer forma de hierarquização dos conteúdos e componentes que perpassam o processo formativo.

Além da indissociabilidade entre estágio e supervisão (acadêmica e de campo), da defesa da interdisciplinaridade, da unidade teoria-prática, da articulação entre formaçãoexercício profissional, universidade-sociedade e investigação-intervenção, as Diretrizes Curriculares (ABEPSS, 1996), preconizam no processo de estágio a indissociabilidade entre as dimensões teórico-metodológica, ético-política e técnico-operativa. Tendo em vista que a realização do estágio deve ocorrer em conformidade com os princípios ético-políticos estabelecidos no Código de Ética Profissional de 1993, é de suma importância que seja assegurada a transversalidade da ética (assim como da pesquisa e do ensino da prática) na formação profissional. Isso significa que as discussões sobre os fundamentos éticos, a pesquisa e o exercício profissional não podem se restringir a uma disciplina específica, mas perpassar todos os conteúdos curriculares.

Desde a elaboração das Diretrizes Curriculares em 1996, o estágio ganhou centralidade no processo formativo, adensando os debates coletivos da categoria profissional e a produção de conhecimento sobre o tema ${ }^{4}$. Em âmbito nacional também são observadas mudanças significativas sobre a concepção de estágio, inclusive nos instrumentos normativos e legais, como se verifica com a promulgação da Lei de Estágio n. 11.788, de 25/09/2008, que passa a entender o estágio como ato educativo que pressupõe supervisão. Em seguida, considerando essas mudanças e um amplo debate já em curso na categoria profissional, é publicada pelo CFESS a Resolução n. 533, de 29/09/2008, regulamentando a supervisão direta de estágio como atribuição privativa de assistentes sociais. A partir desse movimento histórico e considerando as demandas da profissão de avançar no debate teórico-político do estágio, de forma a assegurar qualidade e criticidade na formação, a categoria profissional se organizou coletiva e democraticamente e, por meio de encontros e debates, foi elaborada, no biênio 2009-2010, a Política Nacional de Estágio (PNE) ${ }^{5}$. 
A PNE estabelece princípios e diretrizes basais em defesa de uma formação crítica e de qualidade, tendo como referência as Diretrizes Curriculares de 1996, da ABEPSS, e o projeto ético-político do Serviço Social brasileiro. A construção da PNE foi um compromisso prioritário assumido pela gestão da ABEPSS (2009-2010), tendo em vista os recentes desdobramentos políticos e conjunturais da sociabilidade burguesa neoliberal, marcada pela hegemonia do capital financeiro, desregulamentação e intensificação do trabalho, reformas estruturais na política educacional, precarização do ensino superior e do trabalho docente, expansão dos cursos de Serviço Social e mudanças legislativas sobre a concepção de estágio. Emerge como um instrumento político de defesa de um projeto crítico de formação profissional que caminha no contrafluxo dos interesses e prerrogativas do capital, pois, nos últimos anos, o que se observa é uma expansão de cursos superiores no contexto de mercantilização da educação, de aligeiramento da formação, com ênfase na tecnificação, no pragmatismo e prevalência de uma razão instrumental (GUERRA, 1995) ${ }^{6}$.

Nesse cenário de profundas transformações societárias que também trouxeram desdobramentos para o Serviço Social, ocorreu uma ampla mobilização e organização da categoria profissional de forma a construir estratégias e alternativas que pudessem assegurar a sustentação hegemônica do projeto ético-político do Serviço Social. Dentre estratégias e proposições, a PNE, como instrumento político de luta contra a precarização do ensino superior e defesa do projeto de formação profissional crítico, apresenta princípios balizadores do estágio no processo de formação, apontando a necessidade de construção e fortalecimento dos Fóruns de Supervisão de Estágio como espaços por excelência de debate, de interlocução, de articulação, de formação continuada, de luta e de resistência frente aos inúmeros desafios postos na realidade social.

A constituição dos Fóruns de Supervisão de Estágio em Serviço Social assumiu significativa importância e protagonismo nos últimos anos, diante de uma conjuntura social marcada pelo célere crescimento do ensino superior no Brasil e caracterizada pela aceleração do processo formativo. Foi especialmente a partir dos anos 2000 que ocorreu uma crescente oferta de cursos de Serviço Social em todas as esferas do ensino superior, tanto pública, quanto privada, e em todas as modalidades, presencial e a distância, pois nesse período "a educação superior aparece no mundo mercantil como campo dos mais promissores ao lucro" (KOIKE, 2009, p. 205).Dentre as tendências identificadas na expansão do ensino superior no país, destacamos o Plano de Reestruturação e Expansão das Universidades Federais (REUNI), por meio do decreto n. 6.096, de 24/04/ 2007, o decreto n. 5622, de 19 de dezembro de 2005, que institui a educação a distancia (EaD) em âmbito nacional e o decreto n. 5.800 de oito de junho de 2006 que dispõe sobre a Universidade Aberta do Brasil (UAB). Esses determinantes provocam rebatimentos diretos na formação profissional em Serviço Social, pois:

O ensino on-line que move a EaD, no âmbito da graduação, apresenta-se com o discurso da democratização do acesso, favorecendo a expansão desordenada da educação superior a baixo custo. Como 'ensino fabril', a EaD no âmbito da graduação consolida a mercantilização da educação no país conferindo-lhe caráter discriminatório ao criar dois tipos de ensino, de formação, de aluno e de docente (KOIKE, 2009, p. 207).

Esse cenário de transformações societárias, de crise capitalista e de prevalência dos interesses mercantis sob a lógica da reprodução ampliada do capital, demanda da categoria profissional um posicionamento político e crítico para apreender rigorosamente a realidade contemporânea, pensando estratégias e assumindo compromissos coletivos na defesa do projeto ético-político, que tem na liberdade sua referência e centralidade.

Nessa conjuntura de tensos embates na relação capital/trabalho, a categoria profissional busca se fortalecer coletivamente por meio das articulações com as entidades representadas pelo conjunto CFESS/CRESS, ABEPSS, ENESSO, além de outras organizações da classe trabalhadora e movimentos sociais. As entidades representativas constituem hoje um patrimônio político em defesa da profissão, consonante com as lutas sociais mais amplas da classe trabalhadora, e de um projeto ético-político sintonizado com um projeto de sociedade que tem como horizonte uma perspectiva emancipatória.

Nas três últimas décadas, o serviço social brasileiro construiu coletivamente um patrimônio sociopolítico e profissional que lhe atribui uma face peculiar no cenário da América Latina e Caribe. Dessa herança progressista fazem parte entidades fortes politicamente, representativas e articuladas entre si, com legitimidade política e capilaridade organizativa inédita nesses tempos de combate à luta social e exaltação do individualismo e da indiferença ante os dramas coletivos. O patrimônio intelectual e político, construído pelo serviço social brasileiro, tem no seu núcleo central a compreensão da história a partir das classes sociais e suas lutas, o reconhecimento da centralidade do trabalho e dos trabalhadores. Ele foi alimentado teoricamente pela tradição marxista - no diálogo com outras matrizes analíticas - e politicamente pela aproximação às forças vivas que movem a história: as lutas e os movimentos sociais (IAMAMOTO, 2013, p. 335-336). 
Diante desse quadro pode-se reconhecer a importância das entidades político-representativas como patrimônio da categoria na defesa de uma formação profissional crítica, de qualidade, pública e do projeto ético-político. A construção dos Fóruns de Supervisão de Estágio é resultado da capacidade política de articulação, mobilização e organização da categoria profissional. Isso significa que os Fóruns precisam ser construídos e organizados mediante a interlocução entre os sujeitos envolvidos no processo de supervisão de estágio, como as Unidades de Formação Acadêmica (UFAs), supervisores de campo e acadêmicos, estudantes/estagiários, coordenadores de estágio e/ou de curso. Também é fundamental o apoio, suporte e contribuição da ABEPSS, ENESSO e do conjunto CFESS/CRESS, pois a supervisão de estágio, sendo componente curricular obrigatório da formação e relacionada ao exercício profissional, envolve todos esses sujeitos e entidades representativas. Além do mais, a constituição dos Fóruns, seja local, estadual, distrital, regional e/ou nacional, é uma estratégia essencial para o fortalecimento da PNE e para a garantia de um estágio com as condições indispensáveis de uma formação crítica e de qualidade.

\section{Fórum de supervisão de estágio: espaço de articulação, resistência e luta}

Tem sido recorrente a realização dos Fóruns de Supervisão de Estágio em âmbito nacional diante da atual conjuntura, das necessidades e demandas apresentadas no processo formativo e de supervisão. A partir da elaboração coletiva e democrática da PNE no biênio 2009-2010, os Fóruns ganharam maior evidência e centralidade no debate sobre o estágio, sendo este espaço o lócus por excelência de discussão das inúmeras questões que envolvem o processo formativo e o exercício profissional na sua relação com a dinâmica societária. O quadro observado recentemente é a constituição de Fóruns em todos os âmbitos: local, estadual, distrital, regional e nacional. Isso porque a categoria tem empreendido esforços para a construção e consequentemente para o fortalecimento desses espaços como forma de interlocução entre os sujeitos profissionais, articulação, mobilização, resistência e luta coletiva. Os Fóruns, organizados como atividade permanente, também têm sido espaços fecundos para o processo de formação continuada, tendo em vista os debates realizados e seus desdobramentos em ações político-pedagógicas. A construção e consolidação dos Fóruns significam avanços no âmbito da capacidade político-organizativa da profissão, tendo como horizonte a defesa de uma formação crítica, de qualidade e com direção social, intelectual e ideopolítica estratégica, vinculando organicamente formação e exercício profissional. Por isso, conceber e dar materialidade aos Fóruns de Supervisão demonstra o amadurecimento da profissão no que se refere aos seus aportes e referenciais teóricos, metodológicos, éticos e político-organizativos. Além disso, os Fóruns também permitem a superação de uma análise academicista do estágio, explicitando a necessidade de articulação e vínculo entre as universidades, os campos de estágio e as entidades político-representativas, num processo intermitente de ensino-aprendizagem e organicidade da categoria.

Apresentaremos alguns indicadores, com base nas experiências com a realização dos Fóruns de Supervisão na regional centro-oeste, que são resultantes dos inúmeros esforços empreendidos, compromissos políticos assumidos e articulações estabelecidas entre as entidades representativas da categoria, as universidades, supervisores de campo e acadêmicos, estagiários e coordenadores de curso e/ou estágio.

No ano de 2013, a gestão da ABEPSS (2013-2014), se reuniu nos dias quatro e cinco de março em Florianópolis, Santa Catarina, para o planejamento de suas ações. Nessa reunião foi composta uma comissão, envolvendo representantes de todas as regionais (Norte, Nordeste, Centro-Oeste, Leste, Sul I e Sul II), com o objetivo de realização de um mapeamento dos Fóruns de Supervisão existentes no Brasil, enfatizando: constituição, organicidade, periodicidade, ações desenvolvidas, perfil dos participantes, estratégias e desdobramentos desses Fóruns, com o propósito de socialização e publicização dos dados posteriormente.

Na Oficina Nacional de Graduação e Pós-Graduação da ABEPSS realizada em Goiânia-GO, de quatro a seis de dezembro de 2013, na Pontifícia Universidade Católica de Goiás, e que teve como tema Universidade, formação profissional e diretrizes curriculares: desafios para o Serviço Social Brasileiro, a comissão apresentou os resultados preliminares da pesquisa que ainda se encontra em andamento, devido sua natureza ampla e complexa.

Dentre os dados apresentados e que subsidiaram a pesquisa nacional, encontram-se aqueles que foram identificados também na regional centro-oeste, a partir da realização de Fóruns locais, estaduais, distrital e regional realizados no biênio 2013-2014. É importante destacar que além da realização dos Fóruns Locais que acontecem de forma contínua e sistemática na região (bimestral, semestral ou anualmente), foram realizados, pela primeira vez, os Fóruns Estaduais em Goiás e em Mato Grosso em 2013, além do $2^{\circ}$ Fórum Distrital em Brasília, pois o $1^{\circ}$ Fórum Distrital ocorreu em 2012 na Universidade de Brasília (UnB).

O $1^{\circ}$ Fórum Regional de Supervisão de Estágio do Centro-Oeste ocorreu na cidade de Cuiabá, em sete de novembro de 2013, na Universidade Federal de Mato Grosso (UFMT), contando com a participação de 
instituições de ensino públicas e privadas, representantes das entidades da categoria, coordenadores de curso e/ou estágio, supervisores de campo, supervisores acadêmicos e estudantes.

Já o $2^{\circ}$ Fórum Regional de Supervisão de Estágio ocorreu em Brasília, em 16 de outubro de 2014, na Universidade de Brasília (UnB), e também contou com ampla participação de profissionais, estudantes, universidades e entidades da categoria.

A construção do Fórum Regional Centro-Oeste de Estágio resulta da articulação da ABEPSS com as universidades, o CRESS de cada estado, por meio das Comissões de Formação Profissional e a ENESSO, visando potencializar e propiciar espaços de discussão coletiva sobre a formação e o processo de supervisão de estágio em Serviço Social. Os Fóruns até então realizados, permitiram acumular experiências sobre o processo de supervisão de estágio, enfatizando potencialidades e dificuldades encontradas pelas universidades no que se refere à consolidação dos princípios orientadores da PNE.

A partir da realização dos Fóruns, várias questões foram problematizadas e, por isso, apresentaremos alguns elementos considerados recorrentes nos desdobramentos e repercussões desses espaços, com base em um questionário elaborado pela ABEPSS Regional Centro-Oeste e utilizado nos Fóruns do Distrito Federal, Goiás e Mato Grosso. O questionário objetivou abranger questões sobre a formação profissional, o espaço sócio-ocupacional, os desafios, os limites e as estratégias no processo de supervisão, além de indicar sugestões e propostas para os próximos encontros dos Fóruns?

É importante ressaltar, com base nos dados que serão apresentados, que não pretendemos fazer análises reducionistas e/ou generalistas, mas situá-los como demandas e expressões de uma realidade que é, sem dúvida, mais ampla e complexa. Dentre as ponderações apresentadas, merece destaque as limitações sobre a participação contínua de profissionais nos Fóruns, o que pode ser associado ao processo de precarização do trabalho, caracterizado pela sobrecarga, pressão institucional, cumprimento de metas e intensificação das atividades laborativas. Isso impossibilita que muitos profissionais participem das atividades do Fórum. Foi significativa a participação coletiva em 2013, sobretudo nos estados de Mato Grosso e Goiás, onde os fóruns ocorriam pela primeira vez.

No Distrito Federal, em 2013, ocorreu a $2^{\mathrm{a}}$ edição do Fórum Distrital de Supervisão. Nos respectivos Fóruns da região, no período correspondente, mais de seiscentas pessoas participaram desses espaços, sendo que 306 responderam aos questionários elaborados pela ABEPSS Regional, dentre as quais, $19 \%$ no Distrito Federal, 36\% em Goiás e 45\% em Mato Grosso. A participação mais significativa numericamente foi a de estudantes, seguida pelos assistentes sociais (tanto supervisores de campo, quanto não supervisores) e docentes (tanto supervisores acadêmicos, quanto não supervisores), respectivamente.

Dos 92 assistentes sociais/supervisores de campo que participaram desses Fóruns (abarcando Goiás, Mato Grosso e Distrito Federal) e que responderam ao questionário proposto, 35\% se formaram no período de 2008 a 2013, sendo que 62\% se formaram em UFA pública e 95\% no ensino presencial. Além disso, 58\% possuíam pós-graduação, $80 \%$ estavam inseridos em instituições públicas, sendo que $43 \%$ trabalhavam no serviço público municipal. Sobre a jornada de trabalho, $48 \%$ trabalhavam 30 horas semanais. Sobre o acompanhamento sistemático do estágio pelas UFAs e supervisão acadêmica, $51 \%$ responderam que são realizadas as visitas, encontros e reuniões permanentemente.

Em relação aos 193 estudantes que participaram e responderam ao questionário, identificamos que a maioria dos campos de estágio que absorvem os estagiários ainda se concentra na área da saúde (21\%) e da assistência social (20\%), sendo que 39\% não responderam ao questionário. Esse alto índice de não respostas deve-se ao fato de que alguns estudantes ainda não estavam inseridos no estágio ou não tinham sido alocados até o momento.

Quanto aos 21 supervisores acadêmicos participantes e que responderam ao questionário, $52 \%$ estavam vinculados às instituições privadas de ensino, sendo $95 \%$ do ensino presencial. Todos os supervisores acadêmicos responderam que o estágio na sua UFA se organiza em formato de disciplina e $48 \%$ acompanham mais de 10 estudantes em estágio, o que contribui para a sobrecarga de trabalho e dificulta o acompanhamento contínuo e sistemático da supervisão. Também se observa que sendo considerado um espaço de formação continuada, a partir dos Fóruns são realizados e propostos cursos, mini-cursos, palestras e demais eventos. Porém, mesmo com conquistas observadas com a construção dos Fóruns, ainda se identificam dificuldades e desafios que precisam ser superados. Também foram apresentadas possíveis estratégias e alternativas para o enfrentamento coletivo dos desafios presentes e apontadas propostas relacionadas às contribuições da ABEPSS com os Fóruns de Supervisão. O quadro a seguir esboça, de forma sintética, as respostas obtidas com base nos questionários aplicados nos Fóruns de Supervisão de Estágio na regional Centro-Oeste no biênio 2013-2014.

Os debates ocorridos nos Fóruns da regional centro-oeste foram de suma relevância, sobretudo pela indicação de uma agenda de compromissos, encaminhamentos e lutas para pensarmos estratégias coletivas diante de uma realidade que nos desafia cotidianamente. Espaços de interlocução como os propiciados pelos 
Fóruns possibilitam acúmulo, aprofundamento e diálogo crítico permanente entre os diversos sujeitos envolvidos no processo de formação e exercício profissional.

Dentre as formas de enfrentamento coletivo das questões identificadas nos Fóruns, a gestão da ABEPSS (2013-2014) apresentou como proposta da 2 edição do Projeto ABEPSS Itinerante para o ano de 2014, a discussão do tema: Estágio Supervisionado em Serviço Social: desfazendo os nós e construindo alternativas. Isso significa que o debate sobre o estágio tem sido preocupação e pauta constante da categoria profissional.

\section{Comentários finais}

Tendo em vista o quadro atual de ofensiva capitalista e a necessidade de construção e fortalecimento de espaços estratégicos coletivos, como é o caso dos Fóruns, observamos a importância de articulação entre as entidades representativas, como o conjunto CFESS/CRESS, ABEPSS e ENESSO, com as universidades e todos os sujeitos profissionais envolvidos nesse processo, como os supervisores de campo, supervisores acadêmicos, estagiários e coordenadores de curso e/ou estágio.

Na sociabilidade capitalista, que se utiliza de inúmeros mecanismos para desmobilizar as organizações da classe trabalhadora, é preciso ampla mobilização e organização de assistentes sociais, no sentido de defesa do patrimônio político e intelectual conquistado. Para isso, o Serviço Social precisa assegurar sua capacidade organizativa, tendo como referência as entidades representativas da categoria e estabelecer alianças com demais forças sociais e segmentos vinculados aos interesses da classe trabalhadora, em defesa de um projeto emancipatório de sociedade. Nesse ínterim, o Fórum de Supervisão de Estágio constitui-se e se afirma como espaço político-formativo estratégico de resistência, mobilização, interlocução e luta em defesa de uma formação profissional de qualidade, crítica, laica, pública, presencial, democrática e do projeto ético-político afinado com um projeto societário emancipatório. Considerando a necessidade de construção e consolidação dos Fóruns, as entidades representativas e os sujeitos envolvidos com o estágio supervisionado necessitam priorizar atividades do Fórum, planejando suas ações, acompanhando e avaliando sistematicamente seus desdobramentos, impactos e desafios.

Como a PNE preconiza, as atividades do Fórum poderão ser organizadas e realizadas de forma itinerante, ou seja, envolvendo diferentes universidades e espaços sócio-institucionais relacionados com a formação e o exercício profissional, o que também contribui para o fortalecimento de vínculos político-organizativos entre os sujeitos profissionais e as entidades representativas. Nesse cenário, identificamos que inúmeros são os desafios, mas a capacidade histórica e política da categoria profissional de superá-los é ainda maior. Assim, é preciso avançar na luta e na resistência coletiva e os Fóruns de Supervisão de Estágio são espaços privilegiados para isso.

\section{Referências}

ABEPSS. Proposta básica para o projeto de formação profissional. Serviço Social e Sociedade, n.50. São Paulo: Cortez, p.143-171, 1996.

. Diretrizes Gerais para o curso de Serviço Social. Rio de Janeiro, 1996.

. Política Nacional de Estágio - PNE. Brasília: ABEPSS, 2009.

ACQUAVIVA, Marcus Cláudio. Dicionário Jurídico Acquaviva. São Paulo: Redieel, 2015.

BRASIL. Lei n.11.788, de 25 de setembro de 2008. Dispõe sobre o estágio de estudantes e dá outras providências. Brasília, 2008.

CFESS. Resolução n.533, de 29 de setembro de 2008. Regulamenta a supervisão direta de estágio em Serviço Social. Brasília: CFESS, 2008.

Código de Ética do/a Assistente Social. Brasília: CFESS, 2012.

GUERRA, Y. A instrumentalidade do Serviço Social. São Paulo: Cortez, 1995.

IAMAMOTO, M. Serviço Social em tempo de capital fetiche: capital financeiro, trabalho e questão social. São Paulo: Cortez, 2007. . O Brasil das desigualdades: “questão social”, trabalho e relações sociais. Revista Ser Social, v.15, n.33. Brasília, p.326-342,

2013.

KOIKE, M. M. Formação profissional em Serviço Social: exigências atuais. In: CFESS; ABEPSS. Serviço Social: direitos sociais e competências profissionais. Brasília: CFESS; ABEPSS, 2009.

LEWGOY, A. M. B. Supervisão de estágio em Serviço Social: desafios para a formação e o exercício profissional. São Paulo: Cortez, 2009.

NETTO, J. P. Ditadura e Serviço Social: uma análise do Serviço Social no Brasil pós 64. São Paulo: Cortez, 2001.

. Transformações societárias e Serviço Social: notas para uma análise prospectiva da profissão no Brasil. Revista Serviço Social e Sociedade, n.50. São Paulo: Cortez, ano XVII, p. 87-132, 1996. 
YAZBEK, M. C. O significado sócio-histórico da profissão. In: CFESS; ABEPSS. Serviço Social: direitos sociais e competências profissionais. Brasília: CFESS; ABEPSS, 2009.

\section{Notas}

1 Regional centro-oeste refere-se à divisão político-organizativa da Associação Brasileira de Ensino e Pesquisa em Serviço Social (ABEPSS). Abrange os estados de Goiás, Mato Grosso e o Distrito Federal, não seguindo a mesma lógica de distribuição geográfica das regiões do país, a partir do seu mapa físico-político, que inclui o Mato Grosso do Sul.

2 Adotamos a terminologia Fórum de Supervisão ao invés de Fórum de Supervisores entendendo que esse espaço não se restringe à participação de supervisores de estágio (acadêmicos e de campo), mas abrange também outros sujeitos como: estudantes-estagiários, representantes das entidades político-organizativas da profissão, além de docentes e assistentes sociais que mesmo não tendo assumido atribuições de supervisão até o presente momento, são considerados potenciais supervisores.

3 Conforme Acquaviva (2015), Dicionário Jurídico.

4 Como exemplo de conhecimentos produzidos sobre a supervisão de estágio, consultar Lewgoy (2009).

5 Já havia naquele momento indicativos que sinalizavam àABEPSS sobre a necessidade de construção de uma Política Nacional de Estágio, como pode ser observado no relatório disponibilizado no XI Encontro Nacional de Pesquisadores em Serviço Social (ENPESS), realizado em São Luís, Maranhão, em 2008, referente à pesquisa avaliativa de implementação das Diretrizes Curriculares e também a moção aprovada na deliberação do $37^{\circ}$ Encontro Nacional CFESS/CRESS, ocorrido em Brasília em 2008.

6 Segundo Guerra (1995), a razão instrumental se caracteriza pela fragmentação, descontextualização, imediaticidade, espontaneísmo, manipulação de instrumentos e operações formal-abstratas. A razão instrumental se contrapõe à razão crítica-dialética, que se caracteriza pela apreensão do movimento histórico, tendo como fundamento as mediações, as contradições e a totalidade.

7 Foi informado aos sujeitos que participaram dos Fóruns e responderam aos questionários sobre os objetivos da pesquisa e respectiva publicização dos dados. A participação foi facultativa e todos os respondentes assinaram o Termo de Consentimento Livre e Esclarecido (TCLE), seguindo as recomendações éticas.

\section{Reginaldo Guiraldelli}

guiraldelli@unb.br

Doutorado em Serviço Social pela Universidade Estadual Paulista (Unesp)

Professor de Política Social da Universidade de Brasília (UnB)

\section{Janaina Loeffler de Almeida}

janainases@hotmail.com

Mestre em Serviço Social pela Universidade Federal de Santa Catarina (UFSC)

Assistente Social da Secretaria de Planejamento do Estado de Mato Grosso (SEPLAN).

\section{UnB}

Campus Universitário Darcy Ribeiro.

Brasília - Distrito Federal - Brasil

CEP: 70910-900

\section{SEPLAN - MG}

Rua Julio Domingos de Campos, s/n - Centro Político Administrativo

Cuiabá - Mato Grosso - Brasil

CEP: 78049-903 